\title{
Latrine access and utilization among people with limited mobility: A cross sectional study
}

\author{
Berhanu Asfaw ${ }^{1}$, Muluken Azage $2^{*}$ and Gebremedhin Berhe Gebregergs ${ }^{2}$
}

\begin{abstract}
Background: Latrine access is one of the challenges faced by people with physical disabilities that limit their mobility (PPDs) in their home and working environments. Latrines should be designed, built and located such that they are easily accessible and utilizable by PPDs. Therefore, the aim of this study was to determine latrine access and utilization, and explore the challenges in latrine use among PPDs in Bahir Dar city, northwest Ethiopia.

Methods: A cross-sectional study design was conducted from July 15 to August 15, 2014. Data were collected using a structured and pre-tested questionnaire, and focus group discussions. Four hundred nineteen participants were included using a systematic random sampling technique. SPSS version 20 was used for data entry and analysis. Binary logistic regression was used to identify factors associated with latrine utilization. Qualitative data were analyzed using themes.
\end{abstract}

Results: Of 419 participants, 142 (33.9\%) had access to latrines and 173 (41.3\%) had satisfactory latrine utilization. Family support while using latrine $(\mathrm{AOR}=4.7,95 \% \mathrm{Cl}(2.7,8.3)$, latrine accessibility $(\mathrm{AOR}=2.1,95 \% \mathrm{Cl}(1.2,3.7)$ and past latrine modification ( $A O R=3.1,95 \% \mathrm{Cl}(1.8,5.4)$ were factors associated with latrine utilization. Presence of steps at the latrine entrance, privacy while using latrine, absence of handrails, unavailability of family support, narrower latrine door, distant latrine, unclean floor of the latrine and elevated foot rests were challenges mentioned by PPDs.

Conclusions: Latrine access and utilization were low among PPDs. Family members should encourage and support PPDs when they need to use latrine, designing accessible latrines, modifying existing latrines to accommodate PPDs are the areas of interventions to increase latrine accessibility and utilization among PPDs.

Keywords: Latrine access, Latrine utilization, People with limited mobility, Disability

\section{Introduction}

In developed as well as developing countries, people with physical disabilities that limit their mobility (PPDs) face difficulties in their physical environments [1-4]. PPDs generally have poorer health, lower educational achievements, fewer economic opportunities and higher rates of poverty than physically-abled or fully-mobile people, due to lack of access to a range of services [1]. Lack of access to water and sanitation services that are enjoyed and utilized

\footnotetext{
* Correspondence: mulukenag@yahoo.com

${ }^{2}$ School of Public Health, College of Medicine and Health Sciences, Bahir Dar University, P.O.Box 79, Bahir Dar, Ethiopia

Full list of author information is available at the end of the article
}

by those without mobility challenges (either temporary or permanent) is a denial of human rights $[1,3]$.

Sanitation is one of the services that is often inaccessible for PPDs in their homes and communities [1]. Studies have documented that latrines or toilets in public and institutional settings, such as transportation centers, markets, schools and medical facilities are not accessible to PPDs [5-8]. Even at home, accessibility of latrines for PPDs is very limited, affecting their quality of life [9-11]. As with the non-disabled population, correct and consistent use of existing latrines is a challenge. Even when there are disabled-accessible latrines, use of those latrines by PPDs was still low [1]. Lack of knowledge about accessibility issues for PPDs was mentioned as a factor that affects 
the provision of appropriate latrines or toilets for PPDs [1], and behavior change materials and messages may need to be modified to support adoption of improved sanitation behaviors by PPDs.

Access and regular use of sanitation facilities by PPDs in homes and workplaces has an important role in reducing their risk of developing diseases associated with poor sanitation, as well as in promoting their health and prevention of other diseases associated with disability, like under-nutrition [12-14]. Lack of sanitation facilities compels people to practice open defecation which increases the risk of disease transmission for the whole community $[15,16]$. In addition, women with physical disabilities are especially vulnerable to assault when they lack access to a sanitation facility, since they often take advantage of the darkness to relieve themselves, and they cannot outrun an attacker [1].

In Ethiopia, there has been rapid progress on construction of sanitation facilities in all parts of the country since 2003, through the introduction of the Health Extension Program by the Ministry of Health. The availability of improved and shared latrine facilities at household level had increased from $8 \%$ in 2000 to $47 \%$ in 2012 [17]. The second National Health Sector Transformation Plan of Ethiopia set a goal of $82 \%$ latrine coverage to improve sanitation and hygiene across the country by 2019 [18].. However, most nongovernmental organizations and government implementers have not addressed disability-focused latrine access and utilization interventions. In addition, the Millennium Development Goals (MDGs) which had generated concern among the global community did not specifically consider the accessibility of latrines for PPDs [19]. Therefore, the aim of this study was to assess latrine access and utilization; identify factors associated with utilization; and explore challenges related to latrine use, among PPDs in Bahir Dar city, Amhara State, Ethiopia.

\section{Methods and materials}

\section{Study design, setting and source population}

The study used a community-based cross-sectional study design with both quantitative and qualitative methods. The study was conducted from July 15 to August 15, 2014 in Bahir Dar city, the capital of Amhara National Regional State in northwest Ethiopia. The city has a total population of 284,020 (47.5\% male) in nine urban sub-cities [20]. According to the City Labor and Social Affairs Office report (2014), a total of 2,245 people with disabilities (PDs) lived in the city, of which 1,637 (73\%) were people with physical disabilities [21]. Of all the people with physical disabilities in Bahir Dar, only 1,421 (87 \%) lived in households with a latrine [21].

\section{Study population and variables}

The selection criteria included all people with physical disabilities living in the study area, age greater than or equal to 15 years, and who had lived at least six months in a household with some type of a latrine. The dependent variables were access to PPD-accessible latrines (as defined for this study) and utilization, whereas the independent variables to explore latrine utilization by those PPDs with access included socio-demographic characteristics, latrinerelated and environmental factors.

\section{Sample size and techniques}

A single population proportion formula was used to calculate sample size using Epi Info version 3.5.3, and based on the following assumption: $50 \%$ proportion of latrine access among PPDs (since there was no previous study and it gave adequate minimum sample size). The sample size selection included a $5 \%$ of margin of error, $95 \%$ confidence level, and $10 \%$ non-response rate. The final sample size was 422 . Participants were selected using a systematic random sampling technique using list of households that had at least one person with limited mobility of the City Labor and Social Affairs Office as sampling frame. If there were more than one person with limited mobility in a household, lottery method was used to select one participant.

\section{Data collection techniques}

Nine enumerators (four men and five women) and three supervisors were recruited for the study, and one-day training was provided for all of the staff on proper data collection methods and how to facilitate focus group discussions. A structured questionnaire in the local Amharic language was developed and pre-tested. The final version was used to collect the quantitative data, including sociodemographic characteristics of PPDs, latrine-related and environmental factors, and latrine utilization. A focus group guide was used to collect the qualitative data, which covered latrine access and utilization, and challenges for latrine utilization. Four focus group discussions were conducted; two with men participants only and two with women only, based on the RATS guidelines [22]. Students, individuals who had no job at the time of study, private and government employees were focus group discussants. Focus group discussants were selected from different kebeles of the City Administration and were not a subset of the participants in the quantitative survey. In each focus group discussion, there was one facilitator and one note taker, and the discussion was also recorded on an audio tape recorder.

\section{Data analysis}

Data were entered, cleaned and analyzed in SPSS version 20 software. Descriptive statistics such as mean and 
proportion were used to describe the data. Bivariate and multivariable logistic regression analyses were performed to identify factors associated with latrine utilization. In bivariate logistic regression, variables whose $\mathrm{p}$-value is $\leq 0.2$ were retained for multivariable logistic regression analysis. Adjusted odds ratios (AORs) with $95 \%$ CIs were calculated to identify predictors of latrine utilization. The audio data from the focus group discussions were transcribed into text, and the qualitative data were analyzed manually using a content thematic approach, following a framework suggested by the researchers [24].

\section{Operational definitions}

1. People with Physical disabilities is persons who for whatever reason:

a. Cannot walk, and may use a wheelchair, trolley, or other mobility device.

b. Can walk with difficulty, and need support from e.g. crutches, handrail, or person to lean on.

c. Can walk, but experience other physical weakness or lack of coordination including weakness in legs [23].

2. Functional latrine: a latrine that provides services for household members at the time of data collection

3. Satisfactory latrine utilization includes ALL of the following: PPDs live in households with functional latrines and either PPDs self-report using it by themselves or with family support on a regular basis; there are no other means of defecation (potty/bowl) present.

4. Accessible latrine for PPDs includes ALL of the following: PPDs having functional latrine that is sufficiently close to their dwellings ( $\leq 6 \mathrm{~m})$; without any steps; at least $1 \mathrm{~m}$ wide clear path that accommodates any mobility aids (crutches, wheelchair, etc.); a minimum $1 \mathrm{~m}$ door width and 1 $\mathrm{m}$ square latrine room space inside; and presence of handrails [24].

5. Past latrine modification is used for those latrines that have been previously constructed inaccessibly, but they are accommodated or are being made suitable for use by people with disabilities, for example, building wheelchair ramps.

\section{Ethical Considerations}

The study was approved by Ethical Review Committee of College of Medicine and Health Sciences, Bahir Dar University, after reviewing the research protocol including the ethical procedures. A letter of permission was obtained from the Amhara National Regional Health Bureau. Data were collected using interviewer administered questionnaire and observational checklist. Informed oral consent was obtained from each participant and parents (for those participants having age $<18$ years) after explaining the purpose of the study. Participants were assured of confidentiality with regard to all information acquired. In addition, during the interviews, each participant was informed that he or she was free to withdraw at any time from the study.

\section{Results}

\section{Socio-demographic characteristics}

A total of 419 PPDs participated in the study. The majority of the participants, 229 (55\%), were males, and in the age range of $20-24$ years (29\%). The mean age of participants was $29.9 \pm 12.5$ (SD) years. Of the total participants, 188 (45\%) were unable to read and write. By occupation, 169 (40\%) were merchants and $85(20 \%)$ were students. With regard to the income status of the participants, 132 (32\%) had a monthly income of less than or equal to 200 Birr (9.65 US dollar) (Table 1).

\section{Latrine access and utilization, latrine related and environmental factors}

Only $142(34 \%)$ participants had PPD accessible latrine access according to the definition used in this study. One hundred and seventy three participants $(41 \%)$ reported that they always used the latrine in their household (whether it met the definition of PPD accessible latrine or not), 144 (34\%) reported that they used the latrine rarely and $102(24 \%)$ reported that they most often used the latrine. When asked about other places used for urination and/or defecation, 154 (62\%) reported that they used an open field, 61 (25\%) used a potty/bowl and 22 (9\%) used nearby bushes. Of all participants, 173 (41\%) had satisfactory latrine utilization (Table 2).

Two hundred eight (50\%) participants had wide latrine walkways allowing the mobility assistive devices to pass smoothly and the rest, 211 (50\%), had grasses, bushes and other barriers blocking the access path to the latrine. One hundred ninety-one (46\%) participants had at least one experience of falling in the latrine room of which 115 $(60 \%)$ were injured during the fall. Two hundred six (49\%) latrines were modified in the past to make accessible for PPDs. Only 163 (39 \%) latrines were found at recommended distance. Most of the latrines, 277 (66 \%) were inaccessible for PPDs. Only 70 (17 \%) latrines had supporting handrail (Table 2).

\section{Reasons for irregular use of the latrines}

In the survey, inappropriate design (58 \%), 'unclean latrine floor' (21\%), 'open field is convenient' (11\%), and 'too wide squatting holes' (8\%) were reasons mentioned by PPDs for not regularly using the household latrines (Fig. 1). 
Table 1 Socio-demographic characteristics of the respondents in Bahir Dar, Northwest Ethiopia, $2014(n=419)$

\begin{tabular}{|c|c|c|c|}
\hline Variable & Category & Frequency & Percent \\
\hline \multirow[t]{6}{*}{ Age } & $15-19$ & 66 & 15.8 \\
\hline & $20-24$ & 123 & 29.4 \\
\hline & $25-29$ & 79 & 18.9 \\
\hline & $30-34$ & 39 & 9.3 \\
\hline & $35-39$ & 32 & 7.6 \\
\hline & $\geq 40$ & 80 & 19.1 \\
\hline \multirow[t]{2}{*}{ Sex } & Male & 229 & 54.7 \\
\hline & Female & 190 & 45.3 \\
\hline \multirow[t]{4}{*}{ Marital Status } & Single & 199 & 47.5 \\
\hline & Married & 138 & 32.9 \\
\hline & Divorced & 61 & 14.6 \\
\hline & Widowed & 21 & 5.0 \\
\hline \multirow[t]{4}{*}{ Educational Status } & Unable to read/write & 188 & 44.9 \\
\hline & $\begin{array}{l}\text { Read and write } \\
\text { including grade 1-8 }\end{array}$ & 153 & 36.5 \\
\hline & Grade 9-12 & 68 & 16.2 \\
\hline & Certificate and above & 10 & 2.4 \\
\hline \multirow[t]{5}{*}{ Occupational Status } & Employed(any) & 42 & 10.0 \\
\hline & Merchant/IGA activities & 208 & 49.6 \\
\hline & House wife & 88 & 21.0 \\
\hline & Daily laborer & 57 & 13.6 \\
\hline & Jobless & 24 & 5.7 \\
\hline \multirow{4}{*}{$\begin{array}{l}\text { Monthly Income } \\
\text { (Ethiopian currency) }\end{array}$} & $\leq 200$ birr & 132 & 31.5 \\
\hline & 201-300 birr & 119 & 28.4 \\
\hline & 301-400 birr & 88 & 21.0 \\
\hline & $\geq 401$ birr & 80 & 19.1 \\
\hline \multirow{2}{*}{$\begin{array}{l}\text { Membership to } \\
\text { disability association }\end{array}$} & Yes & 212 & 49.4 \\
\hline & No & 207 & 50.6 \\
\hline
\end{tabular}

Factors associated with latrine utilization among PPDs

In bivariate logistic regression analysis, age, income, privacy, family support while using latrines, latrine modification in the past and latrine accessibility were factors associated with latrine utilization with a $\mathrm{p}$-value less than 0.2. These variables were further included in the multivariable logistic regression analysis.

In multivariable logistic regression, family support, having a PPD accessible latrine, and past latrine modification had statistically significant associations with latrine utilization. PPDs that have a family support while using latrine were 4.7 times more likely to have satisfactory latrine utilization $(\mathrm{AOR}=4.7,95 \% \mathrm{CI}(2.7,8.3)$. Those PPDs who had accessible latrines were 2 times more likely to have satisfactory latrine utilization than those with inaccessible latrines $(\mathrm{AOR}=2.1,95 \% \mathrm{CI}(1.2,3.7)$. PPDs who made a latrine
Table $\mathbf{2}$ Level of latrine utilization, latrine related and environmental factors among persons with physical disabilities in Bahir Dar city, 2014

\begin{tabular}{|c|c|c|c|}
\hline Variable & Category & Frequency & Percent \\
\hline \multirow{3}{*}{$\begin{array}{l}\text { Frequency of latrine } \\
\text { utilization }\end{array}$} & Always & 173 & 41.3 \\
\hline & Mostly & 102 & 24.3 \\
\hline & Rarely & 144 & 34.4 \\
\hline \multirow{5}{*}{$\begin{array}{l}\text { Means of defecation other } \\
\text { than latrine }(n=246)\end{array}$} & Open field & 153 & 62.3 \\
\hline & Potty/bowl & 61 & 24.7 \\
\hline & Nearby bushes & 22 & 8.9 \\
\hline & Drainage ditches & 8 & 3.2 \\
\hline & Others** & 2 & 0.8 \\
\hline \multirow{2}{*}{$\begin{array}{l}\text { Walkway to latrine allows } \\
\text { mobility assistance device } \\
\text { (wheelchair, crutches, etc.) }\end{array}$} & Yes & 208 & 49.6 \\
\hline & No & 211 & 50.4 \\
\hline \multirow[t]{2}{*}{ Level of latrine utilization } & Satisfactory & 173 & 41.3 \\
\hline & Unsatisfactory & 246 & 58.7 \\
\hline \multirow{2}{*}{$\begin{array}{l}\text { Distance of latrine } \\
\text { from household }\end{array}$} & $<=6$ metaers & 163 & 38.9 \\
\hline & $>6 \mathrm{~m}$ & 256 & 61.1 \\
\hline \multirow[t]{2}{*}{ Latrine accessibility } & Accessible & 142 & 33.9 \\
\hline & Inaccessible & 277 & 66.1 \\
\hline \multirow{2}{*}{$\begin{array}{l}\text { Family support while } \\
\text { using latrine }\end{array}$} & Yes & 239 & 57.0 \\
\hline & No & 180 & 43.0 \\
\hline \multirow[t]{4}{*}{ Type of latrine } & $\begin{array}{l}\text { Traditional dry pit } \\
\text { latrine }\end{array}$ & 315 & 75.2 \\
\hline & $\begin{array}{l}\text { Ventilated } \\
\text { improved pit } \\
\text { latrine }\end{array}$ & 55 & 13.1 \\
\hline & Pour flush latrine & 41 & 9.8 \\
\hline & Others** & 8 & 1.9 \\
\hline \multirow{2}{*}{$\begin{array}{l}\text { Availability of Hand } \\
\text { washing facility }\end{array}$} & Yes & 187 & 44.6 \\
\hline & No & 232 & 55.4 \\
\hline \multirow[t]{2}{*}{ Privacy while using latrine } & Yes & 240 & 57.3 \\
\hline & No & 179 & 42.7 \\
\hline \multirow[t]{2}{*}{ Falling history inside latrine room } & Yes & 191 & 45.6 \\
\hline & No & 228 & 54.4 \\
\hline \multirow{2}{*}{$\begin{array}{l}\text { Injury history when falling in } \\
\text { latrine room }(n=191)\end{array}$} & Yes & 115 & 60.2 \\
\hline & No & 76 & 39.8 \\
\hline \multirow{2}{*}{$\begin{array}{l}\text { Latrine modification in the past } \\
\text { (at least one trial) }\end{array}$} & Yes & 206 & 49.2 \\
\hline & No & 213 & 50.8 \\
\hline
\end{tabular}

Means of defecation other than latrine- Others**- Plastic containment (flying toilets)

Type of latrine- Others** - (Modified bucket type latrines) 


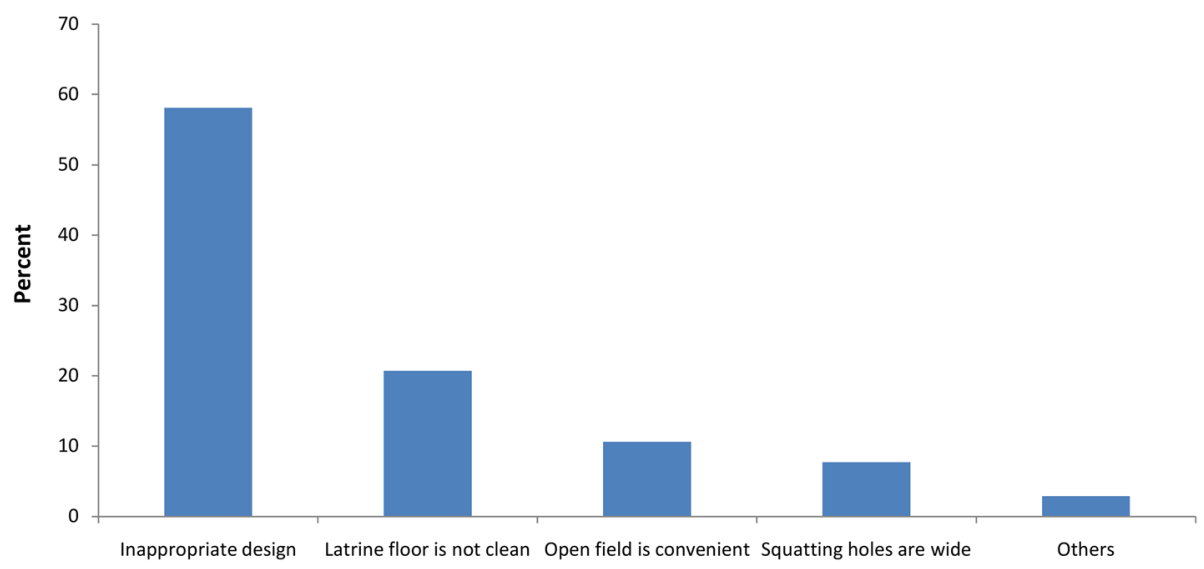

Fig. 1 Reason for irregular use of latrine among persons with physical disabilities in Bahir Dar city, 2014

modification in the past were 3 times more likely to use latrine as compared to PPDs with no past latrine modification $(\mathrm{AOR}=3.1,95 \% \mathrm{CI}(1.8,5.4)$ (Table 3$)$.

\section{Qualitative result}

Seven themes were identified during the exploration of challenges for latrine utilization from the focus group discussions.

\section{Presence of steps at latrine entrance (Theme 1)}

The presence of steps at the entrance of latrine door was raised as a big challenge of PPDs for not using latrine regularly. An 18 year old woman said, "I sometimes intentionally slept hungry in order not to go latrine at night, since the latrine is not accessible. A 22 year old male noted that "when sometimes I fall on latrine steps, my family usually says "Who forced you to use latrine?" and further suggest that it would be fine if I used open field."

\section{Privacy while using latrine (Theme 2)}

A 21 year old female explained that ".... as a female, we need extreme privacy in using the latrine”. A 29 year old man who used a crutch said "Privacy is a significant issue. Take me as an example; I would rather use nearby forests even if it is harder than being seen by others while defecating."

\section{Availability of supporting handrails (Theme 3 )}

Availability of supporting handrails was identified as a barrier to use of latrines that were not PPD accessible. For instance, a 38 year old woman said, "I mostly use the open field because the toilet floor is slippery and there is nothing to hold on the wall."
Family support (Theme 4)

Family support enabled latrine use for PPDs. A 34 year old man said "Above all things, for us, family support is ideal. Even if latrine has design problems, with family support we can always use it. My elder son helps me always while using the latrine."

\section{Narrow latrine door (Theme 5)}

The width of the door to the latrine can cause challenges for access. A 33 year old male explained that "I myself use a wheelchair, and I can't get into the latrine with the wheelchair because the latrine door is narrow and old, and its nails are left sticking out of the wood."

\section{Distance of latrine from household (Theme 6)}

When discussing proximity of the latrine, a 23 year old female student, said that "The lucky ones have their latrine at home". Another 25 year old woman who used two crutches said "There is no question at all about the necessity of latrine. But I always struggle to use it. The struggle starts from the location where it was built. My family latrine is at the corner of our compound and the path to the latrine is covered with bushes and grass."

\section{Unclean floor and elevated squatting foot rests (Theme 7)} A 22 year old woman said that "The main reason for me for not using the latrine regularly is the cleanliness of the floor, it is disgusting and offensive. Some family members, especially young children, are urinating and defecating outside the squatting hole and all day long the latrine floor stays unclean and it's uncomfortable for me to use."

\section{Discussion}

Although presence of a household latrine was one of the selection criteria for the study, latrine access for PPDs (using the definition in this study) was only $34 \%$ of the participants, showing that most available latrines are not 
Table 3 Binary and Multivariable Logistic Regression on factors associated with latrine utilization among PPDs in Bahir Dar, 2014

\begin{tabular}{|c|c|c|c|c|c|}
\hline \multirow[t]{2}{*}{ Variables } & \multirow[t]{2}{*}{ Category } & \multicolumn{2}{|l|}{ Latrine utilization } & \multirow[t]{2}{*}{ COR $(95 \% \mathrm{Cl})$} & \multirow{2}{*}{$\begin{array}{l}\mathrm{AOR}(95 \% \\
\mathrm{Cl})\end{array}$} \\
\hline & & Satisfactory (\%) & Unsatisfactory (\%) & & \\
\hline \multirow[t]{2}{*}{ Sex } & Male & $103(45.0)$ & $126(55.0)$ & $1.4(1.0-2.1)$ & \\
\hline & Female & $70(36.8)$ & $120(63.2)$ & 1.0 & \\
\hline \multirow[t]{6}{*}{ Age } & $15-19$ & $18(27.3)$ & $48(72.7)$ & $0.7(0.3-1.4)$ & \\
\hline & $20-24$ & $61(49.6)$ & $62(50.4)$ & $1.8(1.0-3.3)$ & \\
\hline & $25-29$ & $37(46.8)$ & $42(53.2)$ & $1.6(0.9-3.1)$ & \\
\hline & $30-34$ & $16(41.0)$ & $23(59.0)$ & $1.3(0.6-2.8)$ & \\
\hline & $35-39$ & $13(40.6)$ & $19(59.4)$ & $1.3(0.6-3.0)$ & \\
\hline & $>40$ & $28(35.0)$ & $52(65)$ & 1.0 & \\
\hline \multirow[t]{4}{*}{ Educational status } & Unable to read/write & $74(39.4)$ & $114(60.6)$ & 1.00 & \\
\hline & $\begin{array}{l}\text { Read and write including } \\
\text { grade } 1-8\end{array}$ & $61(39.9)$ & $92(60.1)$ & $1.0(0.7-1.6)$ & \\
\hline & Grade 9-12 (high school) & $31(45.6)$ & $37(54.4)$ & $1.3(0.7-2.3)$ & \\
\hline & Certificate and above & $7(70.0)$ & $3(30.0)$ & $3.6(1.0-14.3)$ & \\
\hline \multirow[t]{5}{*}{ Occupation } & Employed (any) & $18(42.9)$ & $24(57.1)$ & $1.8(0.6-5.3)$ & \\
\hline & Merchant/IGA activities & $95(45.7)$ & $113(54.3)$ & $2.0(0.8-5.1)$ & \\
\hline & House wife & $38(43.2)$ & $50(56.8)$ & $1.8(0.7-4.9)$ & \\
\hline & Daily laborer & $15(26.3)$ & $42(73.7)$ & $0.9(0.3-2.5)$ & \\
\hline & Jobless & $7(29.2)$ & $17(70.8)$ & 1.0 & \\
\hline \multirow{2}{*}{$\begin{array}{l}\text { Membership to disability } \\
\text { association }\end{array}$} & Yes & $21(9.9)$ & $191(90.1)$ & $0.04(0.02-0.1)$ & \\
\hline & No & $152(73.4)$ & $55(26.6)$ & 1.0 & \\
\hline \multirow[t]{2}{*}{ Privacy } & Yes & $112(46.7)$ & $128(53.3)$ & $1.7(1.1-2.5)$ & \\
\hline & No & $61(34.1)$ & $118(65.9)$ & 1.0 & \\
\hline \multirow[t]{4}{*}{ Monthly income (Ethiopian Birr) } & $\leq 200$ birr & $54(34.1)$ & $87(63.9)$ & 1.0 & \\
\hline & 201-300 birr & $50(42.0)$ & $69(58.0)$ & $1.4(0.8-2.3)$ & \\
\hline & 301-400 birr & $36(41.0)$ & $52(59.0)$ & $1.3(0.8-2.3)$ & \\
\hline & $\geq 401$ birr & $42(52.5)$ & $38(47.5)$ & $2.1(1.2-3.8)$ & \\
\hline \multirow[t]{2}{*}{ Family support } & Yes & $139(58.2)$ & $100(41.8)$ & $5.9(3.8,9.4)$ & $4.7(2.7,8.3)$ \\
\hline & No & $34(18.9)$ & $146(81.1)$ & 1.0 & 1.0 \\
\hline \multirow[t]{2}{*}{ Past latrine modification } & Yes & $116(56.3)$ & $90(43.4)$ & $3.5(2.3,5.3)$ & $3.1(1.8,5.4)$ \\
\hline & No & $57(26.8)$ & $156(73.2)$ & 1.0 & 1.0 \\
\hline \multirow[t]{2}{*}{ Latrine accessibility } & Accessible & $76(53.5)$ & $66(46.5)$ & $2.14(1.4,3.2)$ & $2.1(1.2,3.7)$ \\
\hline & Inaccessible & $97(35.0)$ & $180(65.0)$ & 1.0 & 1.0 \\
\hline
\end{tabular}

accessible for PPDs. The reasons might be due to the little attention given by government and non-governmental organizations to support construction of accessible latrines for PPDs, low awareness of PPD needs in latrine design in the communities, and/or lack of financing by households with PPDs. The World Health Organization (WHO) suggests that awareness-raising and challenging negative attitudes are the first steps towards having accessible latrines for PPDs [1].

The latrine utilization rate was $41 \%$, which is in line with the results of a study carried out in Mali on which $42 \%$ of the PPDs regularly used latrines [25]. However, it is lower than the second national health sector transformation plan of Ethiopia: to reach latrine coverage $82 \%$ by the end of 2019 [18]. The low latrine utilization in the current study might be due to low level of awareness and accessibility of latrine for PPDs. The National Hygiene and Sanitation Strategic Action Plan clearly set a strategy of ensuring proper construction and hygienic latrines which could be used by all members including PPDs [26].

Family support in using latrines, latrine accessibility and past latrine modification were factors associated with latrine utilization among people with physical disabilities in 
the study area. PPDs that had family support were 4.7 times more likely to have satisfactory latrine utilization. This is in line with finding from Mali where family support was significantly associated with latrine [27]. Moreover, during the focus group discussions, family support was a principal factor to develop courage and confidence to regularly utilize a latrine.

PPDs with accessible latrines were two times more likely to have satisfactory latrine utilization as compared to their counterparts. The focus group discussion participants outlined the necessity of step-free latrines to support accessibility for those with mobility challenges.

PPDs whose household latrine has been modified in the past were three times more likely to use the latrine as compared to PPDs with no past latrine modification of the standard latrine design. The finding was supported in a focus group discussion, where a latrine was modified with a wider doorway and rope pull to make the latrine more comfortable for a woman using double crutches. Whenever existing latrines are modified to accommodate physically disabled family members, the chance of utilization increases as reported during a disability-focused program by Plan International Kenya in Kilifi, Kenya. The Kenyan study was a good example where disabled people had modified latrines to suit their situation, and the modifications included raised toilet seats, which allow users to sit comfortably, and use of two raised blocks on either side of the drop hole to avoid squatting [28].

This study has some limitations. The cross sectional study design limits the ability to establish cause and effect relationships with the variables and the outcomes. In addition, only mobility issues were included, not other types of disabilities like visual and hearing disabilities.

\section{Conclusions and recommendations}

PPD accessible latrines and latrine utilization were found to be low among people with physical disabilities. Family support, latrine accessibility and past latrine modification were predictors of latrine utilization. Presence of entrance steps, lack of privacy, unavailability of handrails, lack of family support, narrow doors, distant location of latrine and elevated squatting foot rests were challenges mentioned by PPDs in consistently using latrines. Thus, responsible bodies should advocate for and design accessible and inclusive latrines, encourage family members to support people with physical disabilities in using latrines, and modify existing latrines to accommodate people with physical disabilities to improve the situation.

\section{Abbreviations}

PPDs: People with physical disabilities, AOR, Adjusted Odds ratio; $\mathrm{HH}$ : Households; OR: Odds ratio; SPSS: Statistical Package for Social Sciences; WHO: World Health Organization; WASH: Water Sanitation and Hygiene; IGA: Income Generating Activity.

\section{Competing of interests}

The authors declare that they have no competing interest.

\section{Authors' contribution}

BA conceived and designed the study, performed analysis, interpretation of data and drafted the manuscript. MA and GBG assisted with the design, conception, analysis, and interpretation of data and critically reviewed the manuscript. All authors read and approved the final manuscripts.

\section{Acknowledgements}

We are grateful for Bahir Dar University to give chance to study this research project. We also thank Hazel Jones (Loughborough University, UK) and Priscilla Magrath (School of Anthropology, University of Arizona) for sending us valuable disability WASH documents. We would like to thank Dr. Hardeep Rai Sharma from Kurusksherta University, India, for his valuable comment. We are also grateful to the cooperation of the study participants and grateful to Bahir Dar city labor and social affairs Office and Leonard Cheshire foundation for their kind assistance when preparing the proposal and data collection.

\section{Author details}

'Organization for Rehabilitation and Development in Amhara (ORDA), MDG Urban Sanitation Project, P.O.Box 132, Bahir Dar, Ethiopia. ${ }^{2}$ School of Public Health, College of Medicine and Health Sciences, Bahir Dar University,

P.O.Box 79, Bahir Dar, Ethiopia.

Received: 9 October 2015 Accepted: 13 January 2016

Published online: 01 March 2016

References

1. World report on disability. [Internet]. World Health organization. 2011. Available from: http://www.who.int/disabilities/world report/2011/en/.

2. Baird WO, McGrother C, Abrams KR, Dugmore C, Jackson RJ. Access to dental services for people with a physical disability: a survey of general dental practitioners in Leicestershire, UK. Community Dent Health. 2008; 25(4):248-52.

3. Ministry of Gender Labour and Social Development. Accessibility Standards A practical guide to create a barrier free physical environment in Uganda. Uganda National Action on Physical Disability (UNAPD). 2010.

4. Hanass-Hancock J, Alli F. Closing the gap: training for healthcare workers and people with disabilities on the interrelationship of HIV and disability. Disability and rehabilitation. 2015;37(21):2012-21.

5. Popplewell NT, Rechel BP, Abel GA. How do adults with physical disability experience primary care? A nationwide cross-sectional survey of access among patients in England. BMJ open. 2014;4(8):e004714.

6. Allerton L, Emerson E. British adults with chronic health conditions or impairments face significant barriers to accessing health services. Public health. 2012;126(11):920-7.

7. Donnelly C, McColl MA, Charlifue S, Glass C, O'Brien P, Savic G, et al. Utilization, access and satisfaction with primary care among people with spinal cord injuries: a comparison of three countries. Spinal Cord. 2007;45(1): 25-36.

8. Clarke P, Ailshire JA, Lantz P. Urban built environments and trajectories of mobility disability: findings from a national sample of community-dwelling American adults (1986-2001). Social science \& medicine (1982). 2009;69(6): 964-70.

9. Whiteneck G, Meade MA, Dijkers M, Tate DG, Bushnik T, Forchheimer MB. Environmental factors and their role in participation and life satisfaction after spinal cord injury. Arch Phys Med Rehabil. 2004;85(11):1793-803.

10. Mortenson WB, Noreau L, Miller WC. The relationship between and predictors of quality of life after spinal cord injury at 3 and 15 months after discharge. Spinal Cord. 2010;48(1):73-9.

11. Ho PS, Kroll T, Kehn M, Anderson P, Pearson KM. Health and housing among low-income adults with physical disabilities. J Health Care Poor Underserved. 2007;18(4):902-15.

12. Eide A, Loeb M. Living conditions among people with activity limitations in Zambia: a national representative study. Oslo: SINTEF; 2006. p. 2006.

13. Eide A, van Rooy G, Loeb M. Living conditions among people with activity limitations in Namibia: a representative national survey. SINTEF: Oslo; 2003. p. 2003

14. Loeb M, Eide $\mathrm{H}$. Living conditions among people with activity limitations in Malawi: a national representative study. Oslo: SINTEF; 2004. p. 2004. 
15. Clasen TF, Bostoen K, Schmidt WP, Boisson S, Fung IC, Jenkins MW, et al Interventions to improve disposal of human excreta for preventing diarrhoea. The Cochrane database of systematic reviews. 2010(6):Cd007180.

16. Garrett V, Ogutu P, Mabonga P, Ombeki S, Mwaki A, Aluoch G, et al. Diarrhoea prevention in a high-risk rural Kenyan population through pointof-use chlorination, safe water storage, sanitation, and rainwater harvesting. Epidemiol Infect. 2008;136(11):1463-71.

17. WHO/UNICEF. Progress on drinking water and sanitation: 2014 update. Geneva: World Health Organization and New York: United Nations Children's Fund; 2014. 2014.

18. The federal Democratic Republic of Ethiopia Ministry of Health. Health Sector Transformation Plan 2015/16-2019/20. August 2015. Ministry of Health. Addis Ababa, Ethiopia. 2015.

19. Unatied Nation. Disability and the Millennium Development Goals. Department of Economic and Social Affairs, New York. Uniated nation. 2011.

20. Amhara National Regional State Bureau of Finance and Economic Development. Population to size report. Bureau of finance and economic development, Amhara National Regional State (ANRS). 2014.

21. BCLSA. Bahir Dar City Labor and Social Affairs Office (BCLSA) report of 2014. 2014.

22. Springer Open. Qualitative research review guidelines-RATS. http://www. springeropen.com/authors/rats.

23. Jones $\mathrm{H}$, Parker K, Reed R. Water supply and sanitation access and use by physically disabled people. Leicestershire: Loughborough University; 2010

24. Anon. Undoing inequity; inclusive water, sanitation and hygiene programmes that deliver for all in Uganda and Zambia. 36th WEDC International Conference: Nakuru, Kenya. 2013.

25. Tan KS, Norman WR, Knepper S, Kamban N. Access to water, sanitation and hygiene; a survey assessment of persons with disabilities in rural Mali. 36th WEDC International Conference. Nakuru, Kenya; 2013. 2013.

26. MOH. National Hygiene and Sanitation Strategy. Addis Ababa, Ethiopia; 2005. Ministry of Health (MOH) 2005.

27. Horne C, Debeaudrap P. Access to water, hygiene and sanitation for persons in a disabling environment in Mali (region of Tominian). 2007.

28. Jones H. Mainstreaming disability and ageing in water, sanitation and hygiene programmes. A mapping study carried out for Water Aid UK, September 2013: p: 25. 2013.

\section{Submit your next manuscript to BioMed Central and we will help you at every step:}

- We accept pre-submission inquiries

- Our selector tool helps you to find the most relevant journal

- We provide round the clock customer support

- Convenient online submission

- Thorough peer review

- Inclusion in PubMed and all major indexing services

- Maximum visibility for your research

Submit your manuscript at www.biomedcentral.com/submit

) Biomed Central 